\title{
Suizidverhütung als Lebensinhalt und Lebenswerk
}

\author{
Zum 100. Geburtstag von Klaus Thomas
}

Am 31. Januar hätte der stets sozial engagierte evangelische Pfarrer, Psychotherapeut und Mediziner seinen 100. Geburtstag gefeiert. Klaus Thomas ist tot, sein bekanntestes Werk lebt weiter: die Telefonseelsorge. Im Handbuch Telefonseelsorge wird er als deren „Gründervater“ apostrophiert. Angestoßen durch seine Initiative entstanden binnen weniger Jahrzehnte über 100 Telefonseelsorge-Stellen, bundesweit kostenlos erreichbar mit den Rufnummern 0800-1110111 und 08001110222 oder der europäischen Kurzrufnummer 116123. Ein ständiges Gesprächsangebot, ermöglicht von mehr als 8.000 Ehrenamtlichen, offen für jeden Hilfesuchenden, rund um die Uhr, mit jährlich über zwei Millionen Anrufen.

Für Thomas galt Telefonseelsorge als eine Möglichkeit der „Lebensmüdenbetreuung“. Wie weit die Lebensmüdenbetreuung in seiner Vorstellungswelt ging, dass sie bis weit ins Private reichte, bezeugt unter anderem ein von dem Berliner Bischof Otto Dibelius (1880-1967) und ihm verfasster Aufruf: „Weihnachten 1956 braucht niemand zu verzweifeln - Welche Familie ist bereit, einen Einsamen, Verzweifelten, Lebensmüden am Heiligen Abend einzuladen?" Ein Aufruf mit einer beachtlichen Resonanz, wie an einer anderer Stelle zu lesen ist: „Nach dem Austausch von mehreren tausend Adressen blieben rund zehn Familien ohne Gäste übrig.“

Klaus Thomas starb am 10. Juli 1992 im baden-württembergischen Malsburg-Marzell an Herzversagen und fand seine letzte Ruhestätte auf' dem Friedhof Zehlendorf in Berlin. Thomas hinterlie $\beta$ vier Kinder und ein fruchtbares Lebenswerk. Dazu gehört nicht nur die von ihm initiierte Telefonseelsorge, sondern eine Fülle von Publika- tionen sowie die inzwischen im 67. Jahrgang erscheinende Fachzeitschrift „Wege zum Menschen“, deren Initiator und erster Schriftleiter er gewesen ist.

Ein Redner beschrieb ihn bei der Trauerfeier auf dem Zehlendorfer Friedhof am 20. Juli 1992 so: „Sein Arbeiten war gleicherweise ausgerichtet auf theoretische Darstellungen und Erörterungen wie auf sehr praktische Anleitung zu Lebens- und Glaubenshilfe und zu mitverantwortlichem Denken und Handeln. Als seine vornehmste Arbeit sah er aber die individuelle Seelsorge an, die sich mit einem Notleidenden entweder am Telefon oder in vertrauensvollem Zwiegespräch mit seinem Gegenüber vollzog.“

Eine Arbeit, die er nicht nur hierzulande leistete: Thomas bereiste über 80 Länder mit von dem Trauerredner erwähnten Anliegen, darunter Australien, Indien, Nordamerika. Mal war es eine Studien- oder Vortragsreise, dann seine Berufung, etwa in Washington DC, wo er 1964/65 als „staff-psychiatrist“ und Professor für Seelsorge tätig war.

Auskunftsfreudige Reiseberichte sind nicht bekannt. Diese könnten manches erhellen, was sich unter dem Schleier der Geschichte verbirgt. So etwa hinter einer gerahmten Begegnung mit Albert Schweitzer (1875-19658), dem „Urwalddoktor von Lambaréné“ (Gabun). Zeugnis einer Begegnung und eines Briefwechsels von Männern mit Gemeinsamkeiten: evangelische Theologen und Mediziner, der Idee der Nächstenliebe verpflichtet, sich lebensbejahend der Vielfalt der Lebensprobleme widmend. Bei beiden die berufliche Ausrichtung bereits tief verankert und fest verwurzelt in der Herkunftsfamilie. Daran ist wohl kaum zu zweifeln.
Geboren wurde Klaus Thomas am 31. Januar 1915 in Berlin als Sohn der aus dem Pfarrhaus der Berliner Jerusalem-Kirche stammenden Lehrerin Johanna Thomas, geborene Schmeidler, und von Erich Thomas, einem Oberlehrer an der Berliner Gaußschule für Ingenieure. Insofern war der Jubilar ambivalent geprägt: mütterlich durch die pastorale Herkunftsfamilie, andererseits durch die Profession seines Vaters, darüber hinaus durch ein ganz gewiss unvermeidlich pädagogisch eingefärbtes Familienleben, das nicht folgenlos bleiben kann.

Während sich die mütterliche Prägung in seinem sozialen Engagement artikulierte, zeigte sich die andere in einer technischen Versiertheit, wie ein von ihm 1949 erworbenes Patent für den Automobilbau bezeugt. Auch ist zu vermuten, dass diese Prägungen den Nährboden bildeten für die in seinem Lebenswerk sichtbare Kreativität. Diese zeigte sich etwa in dem 1956 von Klaus Thomas ins Leben gerufenen Trägerverein, der bis in die heutige Zeit hinein in Berlin die Finanzierung der ersten und somit eben auch der ältesten deutschen Telefonseelsorge-Stelle gewährleistet, die am 5. Oktober 2016 mit ihren über 150 ehrenamtlichen Telefonseelsorgerinnen und Telefonseelsorgern den 60. Geburtstag begeht.

Franz-Josef Hücker 